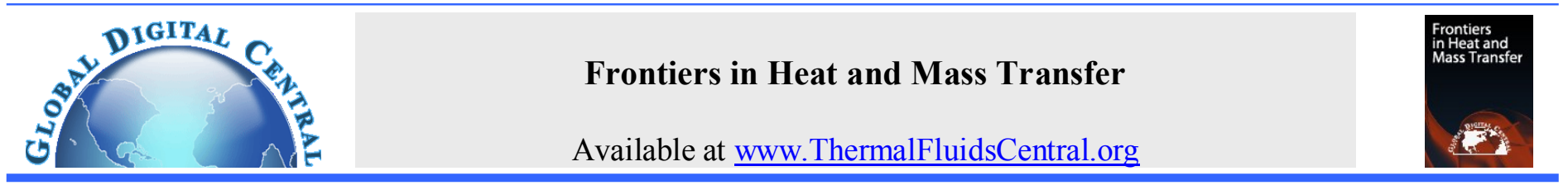

\title{
FLAME STABILITY OF PROPANE-AIR PREMIXED COMBUSTION IN HEAT-RECIRCULATION MICRO-COMBUSTORS
}

\author{
Junjie Chen", Wenya Song, Xuhui Gao, Longfei Yan, Deguang Xu \\ School of Mechanical and Power Engineering, Henan Polytechnic University, Jiaozuo, Henan, 454000, China
}

\begin{abstract}
The flame stability of single-pass heat-recirculation micro-combustors was investigated using computational fluid dynamics and compared to singlechannel micro-combustors with respect to critical heat loss coefficient and total power loss. The effect of wall thermal conductivity was also explored. The simulations show that heat recirculation profoundly affects blowout because of preheating of the cold incoming gases but has only minimal effect on extinction. In the limit of low-conductivity walls, the heat-recirculation micro-combustor is much more stable than the single-channel microcombustor. Under certain conditions, the heat recirculation micro-combustor can operate with room-temperature inlet and outlet streams and moderate outer wall temperatures while exhibiting high thermal and combustion efficiency.
\end{abstract}

Keywords: Micro-combustion; Flame stability; Heat recirculation; Extinction; Blowout; Micro-combustor; Excess enthalpy.

\section{INTRODUCTION}

Micro-scale combustion systems can be used for many applications, including micro-scale thrust and propulsion generation, micro-scale gasturbines and internal combustion engines, and local heat/power production, leading to much attention form the technical community (Cameretti and Tuccillo, 2015; Simagina et al., 2015). The energy density of hydrocarbons is significantly higher than that of conventional batteries, suggesting that even micro-scale devices with poor thermal-toelectric conversion efficiencies can provide superior electrical outputs (Federici et al., 2006; W ierzbicki et al., 2015), and in turn allow for other performance improvements in portable electrical devices, such as a longer lifetime and reduced weight. Aside from portable power, microcombustion will be central to decentralized future energy efforts for supplying the heat necessary to drive endothermic reactions, such as generate steam, reforming and dehydrogenation, etc. (Saito et al., 2015; Vaccaro et al., 2010).

Sustaining combustion at micro-scales is challenging because of large heat losses caused by the large reactor surface-to-volume ratio (Fan et al., 2013; Yang et al., 2015). In addition, radical quenching become more significant at micro-scales (Kizaki et al., 2015). Therefore, fuel-toelectricity conversion devices based on existing macro-scale designs such as internal-combustion-engines may be impractical. Many methods have been employed to promote flame stability, such as many groups have considered "excess enthalpy" micro-combustors for thermal management and piezoelectric, pyroelectric or thermoelectric devices for power generation (Kuo and Ronney, 2007). The geometries of "excess enthalpy" micro-combustor have been used in which the heat released from the combustion region is recycled back to the reaction region (Federici and Vlachos, 2008; Federici et al., 2009). In "excess enthalpy" micro-combustors, the total reactant enthalpy can be higher than that in the incoming cold reactants and can sustain homogeneous flame under conditions that would extinguish without recirculation, such as large heat losses, low heating value fuels, and fuel-lean mixtures (Ronney, 2003;
Scarpa et al., 2009). Two modes of "excess enthalpy" micro-combustors are reverse flow combustors and heat recirculation combustors. In reverse flow micro-combustors, the inlet and outlet fluids are periodically switched, therefore trapping heat within the combustor. This concept has been demonstrated to extend the region of self-sustained homogeneous flame in the single-channel micro-combustor (Kaisare and Vlachos, 2007a). In heat recirculation micro-combustors, thermal energy transfers from combustion products to reactants in a counter-current manner, without mass transfer and allowing heat transfer to preheat the incoming cold mixtures (Shirsat and Gupta, 2011; Yan et al., 2015). The Ronney group has studied heat-recirculating micro-combustors, and found that there are an expansion in flammability limits of the system as compared with single channel micro-combustors (Chen and Ronney, 2011 and 2013). The operation of "Swiss-roll" combustors with gap sizes smaller than the quenching distance were achieved successful by Zhong and Wang (2010). A simple model of counter current heat-recirculating micro-combustors has been developed to study the experimentally observed increase in flame stability and operating conditions of the counter-current exchanger configuration (Ronney, 2003). The excess enthalpy flames and their dynamics behavior in parallel micro-channels have also been modeled and studied (Ju and Choi, 2003; Kurdyumov and Matalon, 2011), where it was observed that heat recirculation across the separating wall allows for increased speed and stability of opposite propagating flames.

Although the above models and studies have successfully explained the effect of heat recirculation, some aspects of this heat-recirculating micro-combustor are still not well understood. For example, to design such micro-scale system, the effect of thermal conductivity (wall material) on flame stability must be explored for optimizing thermal management. Moreover, "Swiss-roll" micro-combustors employ multiple turn method. A simpler micro-scale system could provide very valuable insights to understand the mechanism by which heatrecirculation increases the flame stability. The present work focuses on simple single-pass heat-recirculation micro-combustors that is composed of a central micro-channel similar to previous work (Boyarko et al., 2005; 
Leach and Cadou, 2005; Raimondeau et al., 2002). Hot combustion products are sent in a countercurrent method over the walls of the central micro-channel (combustion chamber) to preheat the cold reactants, instead of leaving the micro-combustor in the form of hot gases. In addition, certainly from a practical standpoint, this single-pass heatrecirculation micro-combustor enables easy integration with other elements, such as endothermic and/or thermoelectrics micro-combustors, in multifunctional devices. Flame stability of this heat-recirculation micro-combustor are discussed and compared to those of the singlechannel micro-combustor. Furthermore, the role of wall thermal conductivity of this micro-scale system in flame stability is elucidated.

\section{NUMERICAL MODELS AND SIMULATION APPROACH}

\subsection{Geometric Model}

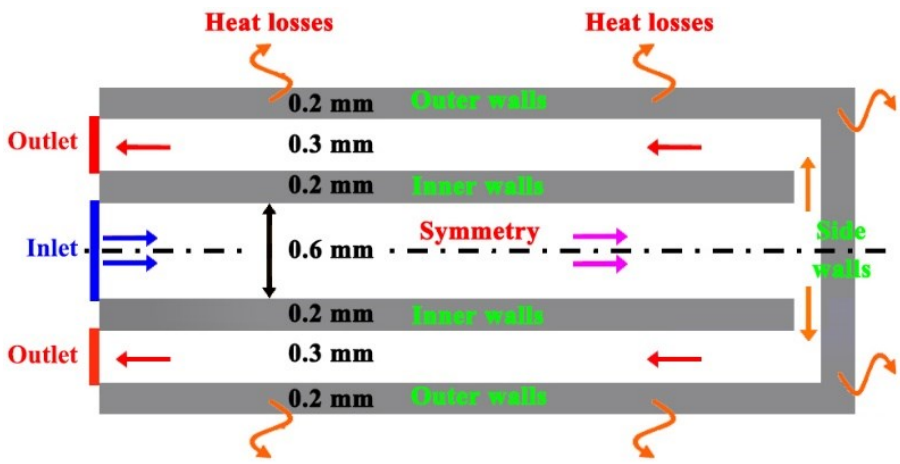

Fig. 1 Schematic diagram of the heat-recirculation micro-combustor.

The heat-recirculation micro-combustor, illustrated in Fig. 1, consists of two outer walls, two inner walls, and side walls. The heat-recirculation geometry implies that the third dimension (width) of this microcombustor is much larger than the gap size. All walls have the same thickness of $0.2 \mathrm{~mm}$ and thermal conductivity. Premixed, stoichiometric propane-air mixtures are fed with a uniform flow velocity into the central combustion-chamber with a gap size of $0.6 \mathrm{~mm}$ at atmospheric pressure and ambient temperature of $300 \mathrm{~K}$. The inlet velocity is $0.5 \mathrm{~m} / \mathrm{s}$. The hot combustion products are split into two streams in recirculation-chambers with a gap size of $0.3 \mathrm{~mm}$ where they are flowed over the walls of the combustion region. The length of combustion region, inner and outer walls are $4.0,3.8$ and $4.0 \mathrm{~mm}$, respectively. The $180^{\circ}$ turns occur at 3.8 $\mathrm{mm}$, i.e., the length of inner outer walls. However, in the "half heatrecirculation micro-combustor" case (the length of combustion region and outer walls are $2.0 \mathrm{~mm}$ ), the turns occur at $1.8 \mathrm{~mm}$.

\subsection{Mathematical Model}

A two-dimensional model is employed to capture species and thermal gradients of the fluid domain in the transverse and axial directions. CFD (computational fluid dynamics) software, FLUENT ${ }^{\circledR}$ Release 6.3 is used to solve the two-dimensional steady state continuity, momentum, energy, and species equations. The laminar-finite-rate model is adopted to consider the interaction between combustion and flow. The governing equations for steady and reactive gas flow with homogeneous reaction are shown below:

Continuity equation:

$$
\begin{aligned}
& \frac{\partial\left(\rho v_{x}\right)}{\partial x}+\frac{\partial\left(\rho v_{y}\right)}{\partial y}=0 \\
& \quad \text { Momentum equation: } \\
& \frac{\partial\left(\rho v_{x} v_{x}\right)}{\partial x}+\frac{\partial\left(\rho v_{x} v_{y}\right)}{\partial y}=-\frac{\partial p}{\partial x}+\frac{\partial \tau_{x x}}{\partial x}+\frac{\partial \tau_{x y}}{\partial y}
\end{aligned}
$$

$$
\begin{aligned}
& \frac{\partial\left(\rho v_{y} v_{x}\right)}{\partial x}+\frac{\partial\left(\rho v_{y} v_{y}\right)}{\partial y}=-\frac{\partial p}{\partial y}+\frac{\partial \tau_{y x}}{\partial x}+\frac{\partial \tau_{y y}}{\partial y} \\
& \text { Energy equation: } \\
& \frac{\partial\left(\rho v_{x} h\right)}{\partial x}+\frac{\partial\left(\rho v_{y} h\right)}{\partial y}=\frac{\partial\left(k_{f} \partial T\right)}{\partial x^{2}}+\frac{\partial\left(k_{f} \partial T\right)}{\partial y^{2}} \\
& +\sum_{i}\left[\frac{\partial}{\partial x}\left(h_{i} \rho D_{i, m} \frac{\partial Y_{i}}{\partial x}\right)+\frac{\partial}{\partial y}\left(h_{i} \rho D_{i, m} \frac{\partial Y_{i}}{\partial y}\right)\right]-\sum_{i} h_{i} R_{i}
\end{aligned}
$$

Species equation:

$$
\frac{\partial\left(\rho Y_{i} v_{x}\right)}{\partial x}+\frac{\partial\left(\rho Y_{i} v_{y}\right)}{\partial y}=-\left[\frac{\partial}{\partial x}\left(\rho D_{i, m} \frac{\partial Y_{i}}{\partial x}\right)+\frac{\partial}{\partial y}\left(\rho D_{i, m} \frac{\partial Y_{i}}{\partial y}\right)\right]+R_{i}
$$

where $\rho, v, p, \tau$ and $T$ denote the density, velocity, pressure, shear stress and temperature, respectively; $h_{i}$ is the enthalpy of the $i$ th species; $k_{f}$ is the thermal conductivity of fluid; $Y_{i}, R_{i}$ and $D_{i m}$ denote the mass fraction, the generation or consumption rate, and the mass diffusivity of the $i$ th species.

Since heat transfer along the wall significantly affects the flame stability (Baigmohammadi et al., 2015a and 2015b; Belmont and Ellzey, 2014; Wierzbicki et al., 2014), heat transfer along the wall is considered in this model. The appropriate energy equation for the solid phase is given as follow:

$$
\frac{\partial\left(k_{s} \partial T\right)}{\partial x^{2}}+\frac{\partial\left(k_{s} \partial T\right)}{\partial y^{2}}=0
$$

where $k_{s}(\mathrm{~W} / \mathrm{m} \mathrm{K})$ represents the thermal conductivity of solid wall.

\subsection{Chemical Kinetics}

In this work, a reduced propane combustion chemistry is used that assumes the irreversible combustion of propane:

$$
\mathrm{C}_{3} \mathrm{H}_{8}+5 \mathrm{O}_{2} \rightarrow 3 \mathrm{CO}_{2}+4 \mathrm{H}_{2} \mathrm{O}
$$

Consequently five species, i.e., $\mathrm{C}_{3} \mathrm{H}_{8}, \mathrm{O}_{2}, \mathrm{CO}_{2}, \mathrm{H}_{2} \mathrm{O}$, and $\mathrm{N}_{2}$, are modeled with corresponding species equations. Specifically, the mechanism used is the one proposed by Westbrook and Dryer (Westbrook and Dryer, 1981),

$$
\begin{aligned}
r_{\mathrm{C}_{3} \mathrm{H}_{8}}\left[\mathrm{kmol} /\left(\mathrm{m}^{3} \mathrm{~s}\right)\right]= & 4.836 \times 10^{9} \cdot \exp \left[\frac{-1.256 \times 10^{8} \mathrm{~J} / \mathrm{kmol}}{R T}\right] \\
& \cdot\left[C_{\mathrm{C}_{3} \mathrm{H}_{8}}\right]^{0.1} \cdot\left[C_{\mathrm{O}_{2}}\right]^{1.65}
\end{aligned}
$$

where $r$ denotes the reaction rate. $R$ is the ideal gas constant, $T$ is the temperature $[\mathrm{K}] . C_{\mathrm{C} 3 \mathrm{H} 8}$ and $C_{\mathrm{O} 2}$ are the molar concentrations $\left[\mathrm{kmol} / \mathrm{m}^{3}\right]$ of propane and oxygen, respectively.

\subsection{Computation Scheme}

The boundary conditions of the heat-recirculation micro-combustor are as follows. Dirichlet's boundary condition for the energy and species equations is used at the inlet. Uniform profiles for the temperature, axial velocity, and species concentrations are specified at the inlet. At the exit, the atmospheric pressure is specified is specified and the remaining fluid parameters are determined by far-field conditions, namely, zero diffusive flux of energy or species normal to the exit. A symmetry boundary condition is employed along the central combustion-chamber and half of the micro-scale system is modeled to minimize the computational intensity. No-slip is considered for both velocity components at gas-solid interfaces; the heat flux at this gas-wall interface is calculated using Fourier's law along with continuity in temperature and heat flux is ensured. The two-dimensional energy equation is solved in the bulk of the wall. The discrete ordinates model is used to consider the effect of interior surface to surface radiation (Kuo and Ronney, 2007). The external surface of the wall, the total heat losses includes both natural convection and thermal radiation, which is calculated as follow:

$q=h\left(T_{w, o}-T_{r e f}\right)+\varepsilon \sigma\left(T_{w, o}^{4}-T_{a m b}^{4}\right)$ 
where $q$ is the heat flux, $h$ is the effective exterior heat transfer coefficient, $T_{w, o}$ is is the exterior temperature of the wall, $T_{a m b}$ is the ambient temperature, $\varepsilon$ is the emissivity of the solid surface, and $\sigma$ is the StephanBoltzmann constant $\left(5.67 \times 10^{-8} \mathrm{~W} /\left(\mathrm{m}^{2} \mathrm{~K}^{4}\right)\right)$. Note that heat transfer is explicitly accounted for all walls and within the fluid streams.

Non-uniform meshes are used with more grids distributed in the combustion region to provide sufficient grid resolution in the computational domain. Grid independence are examined and the final grid density is determined when the profiles of species concentration and temperature do not show obvious difference. The above conservation equations are solved implicitly with the two-dimensional steady-state double-precision segregated solver using the under-relaxation method. The momentum, species, and energy equations are discretized using second-order upwind scheme. The "SIMPLE (semi-implicit method for pressure-linked equations)" pressure-velocity correction algorithm (Patankar and Spalding, 1972) is employed to solve for the pressure and velocity fields. The fluid density is determined from the ideal gas law and the species specific heats are calculated from piecewise polynomial fits. The gas species viscosity, mass diffusivity, and thermal conductivity are calculated from kinetic theory, and the mixture thermal conductivity and viscosity are estimated from mass-weighted and ideal-gas mixing laws, respectively. The convergence of CFD simulation is judged based on the residuals of all governing equations. The simulation results are achieved with residuals smaller than $1.0 \times 10^{-6}$.

\section{RESULTS AND DISCUSSION}

\subsection{Adiabatic Flame Characteristics at the Micro-Scale}

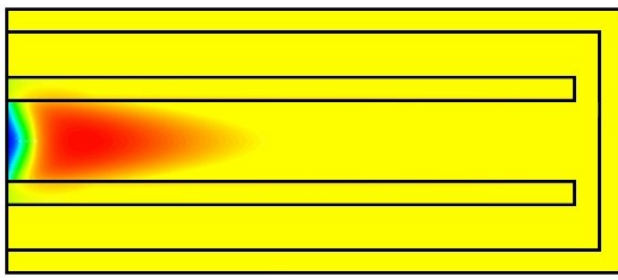

$2280 \mathrm{~K}$

(a) Temperature

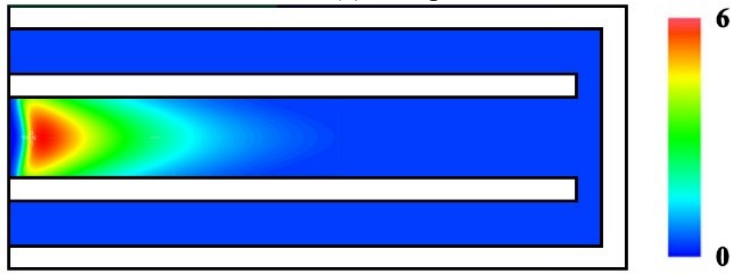

(b) Reaction rate

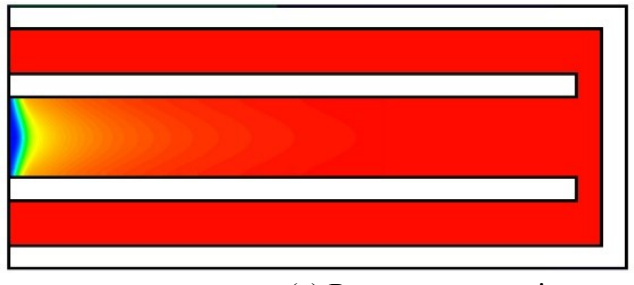

$100 \%$

(c) Propane conversion

Fig. 2 The contours of temperature, reaction rate, and propane conversion for moderate conductive walls $(k=20.0 \mathrm{~W} / \mathrm{m} \mathrm{K})$.

Adiabatic simulations were performed as a function of wall thermal conductivity to delineate the effect of heat exchange in the heatrecirculation micro-combustor. In this case, the term "adiabatic" means that there are no heat losses along the outer walls of the micro-scale system, namely the exterior heat transfer coefficient $h=0$, even though heat is exchanged to the incoming cold reactants by the hot heatrecirculation gases. The only role of walls is to allow for thermal transport within the heat-recirculation micro-combustor, by not allowing for heat loss in the micro-scale system.

The contours of temperature, reaction rate, and conversion for moderate conductive walls are shown in Fig. 2. Propane combustion occurs very rapidly, consuming most of the propane in a very small region (within approximately $2.0 \mathrm{~mm}$ of the entrance). Complete conversion is achieved, and a significant temperature rise is observed because of the exothermicity of the reaction. The flame stabilizes in the center between the two inner walls. The flame location, as a convenient criterion for the robustness or stability of a micro-combustor, is defined as the axial position with the highest reaction rate (Norton and Vlachos, 2003 and 2004). Adiabatic flame corresponds to flame formed without heat losses along the outer walls (Norton and Vlachos, 2003 and 2004; Zimont, 2015). The maximum temperature is higher than the adiabatic flame temperature for stoichiometric propane-air mixtures due to heat transfer from the hot combustion products and the inner walls to the incoming cold reactants, namely as a result of preheating (Belmont et al., 2013 and 2015; Park et al., 2012). Prior to the flame, large temperature gradients exist in the transverse direction.

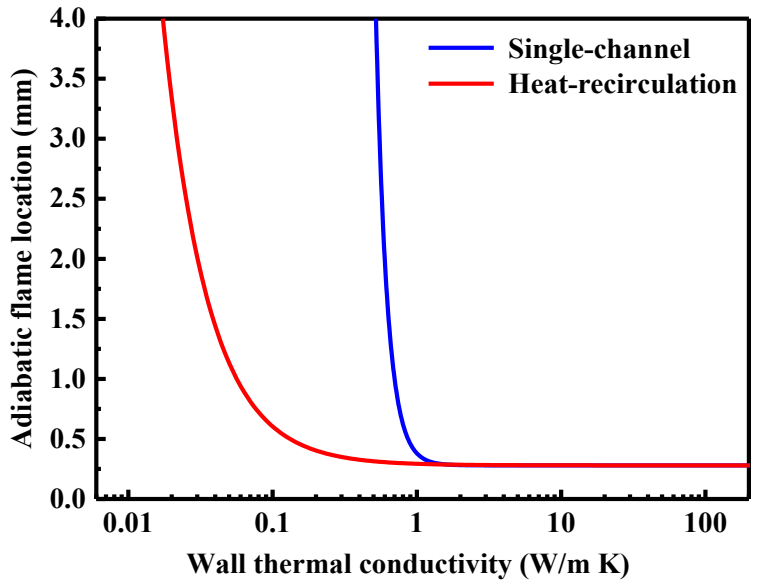

Fig. 3 Adiabatic flame location profiles of various wall thermal conductivities.

The effect of wall thermal conductivity on flame location for the heat-recirculation and single-channel micro-combustors for adiabatic outer walls is shown in Fig. 3. For high wall thermal conductivity, the flame locations for the heat-recirculation and single-channel microcombustors are equivalent. The flame is located very near the entrance over a range of high wall thermal conductivities. As the wall thermal conductivity is reduced, the axial thermal dissipation also reduces. This decreases the amount of preheating from the wall that is required to ignite the cold incoming reactants and sustain combustion. Consequently, this heat transfer limited by low wall thermal conductivity results in the flame location shifting downstream and eventually blowout. Blowout occurs when there is insufficient preheating of the incoming cold reactants to allow ignition and flame stabilization (Norton and Vlachos, 2003 and 2004). The transition from a stable flame near the entrance to blowout is fairly abrupt. The heat-recirculation micro-combustor is able to stabilize the flame using wall thermal conductivities for which the single-channel micro-combustor cannot do so. Therefore, it is clear that the heatrecirculation micro-combustor expands operation limits to low-thermalconductivity walls and prevents blowout of the micro-scale system over a much wider range of materials. In the single-channel micro-combustor, the only mechanism for preheating incoming cold reactants is axial conduction along the wall. In the heat-recirculation micro-combustor, the recirculated hot gases along with the thin inner walls allow for transverse heat exchange. This findings is consistent with conclusions of Ronney in his work with the "Swiss-roll" counter-current micro-combustor (Ahn et al., 2005; Ronney, 2003). In above simulations, the lack of heat losses from the micro-scale system reveals that the enhanced thermal transport 
via the recirculated hot gases causes the increased flame stability of the heat-recirculating micro-combustor.

\subsection{Effect of Heat Losses on Flame Stability}

The motivation behind utilizing "excess enthalpy" micro-combustors is to allow sustained homogeneous flame while enabling outside heat transfer within the forced convection regime. This in turn ensures robust operation when the micro-combustor is a standalone unit or is directly coupled with an adjacent channel carrying out an endothermic reaction (Federici and Vlachos, 2011; Karim et al., 2008). The critical heat loss coefficient is determined for various wall materials to delineate the enhancement in flame stability. This value is obtained using natural parameter continuation, namely, by increasing the exterior heat transfer coefficient from one stationary solution to another, until the flame either quenched or blew out of the micro-scale system. Knowledge of critical parameter values of the exterior heat transfer coefficient gives a better understanding of the important factors controlling flame stability. These critical values are useful as guides, but actual values will vary depending on the system (such as dimensions) of interest.

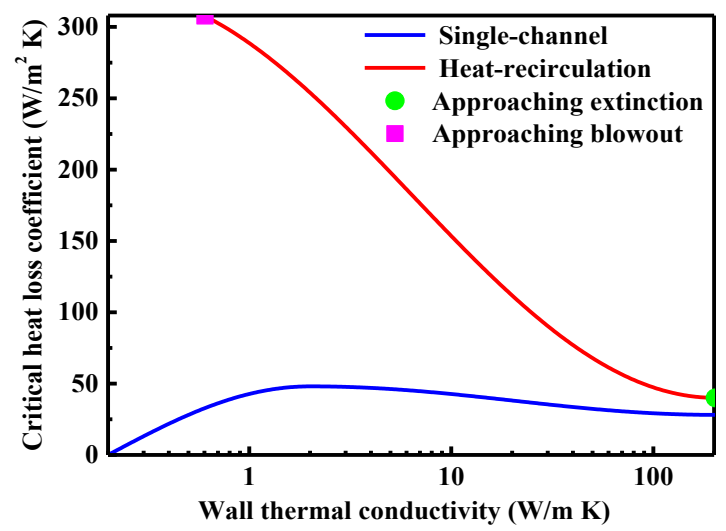

Fig. 4 Critical heat loss coefficient profiles of various wall thermal conductivities. The circle and square represent approaching extinction and blowout, which will be discussed later.

For both the heat-recirculation and single-channel microcombustors, the critical heat loss coefficient profiles as a function of wall thermal conductivity are plotted in Fig. 4. The critical heat loss coefficient values for the single-channel micro-combustor form a nonmonotonic curve that is termed "bell-shaped envelopes" (Kaisare et al., 2008; Norton and Vlachos, 2004). This is a result of the walls playing a competing role in flame stability: walls transfer heat upstream for ignition of the incoming cold reactants but at the same time are responsible for heat losses. Consequently, there is an optimum wall thermal conductivity in terms of flame stability, which appears to be that of common ceramics such as alumina and silica, maximizing the critical heat loss coefficient (Kaisare and Vlachos, 2007b; Kaisare et al., 2009; Norton et al., 2004; Stefanidis and Vlachos, 2009). Low wall thermal conductivity limits the upstream heat transfer along the wall, which limits the preheating of the feed, inhibiting the onset of combustion, and results in blowout. Low wall thermal conductivity also leads to hot spots of high temperatures within the wall, which can result in mechanical failure (Norton and Vlachos, 2003). High thermal conductivity walls are essentially isothermal and have lower temperatures. However, they offer a larger hot area for external heat transfer and become susceptible to spatially global-like extinction (Norton and Vlachos, 2004). The maximum in the bell-shaped envelopes demarcates the transition from the blowout regime (left side of the curve, low wall conductivities) to the extinction regime (right side of the curve, high wall conductivities). The graph also shows two additional cases (symbols, approaching extinction and blowout) that will be discussed later.

The critical heat loss coefficients for the heat-recirculation microcombustor are similar to the single-channel micro-combustor for highly conductive walls. This conclusion is consistent with the results of the adiabatic flame locations shown in Fig. 3, where the two micro-scale systems are also similar. For high-wall-thermal-conductivity materials, there is sufficiently facilitated heat transfer from the flame to the entrance via the walls. As a result, the effect of additional heat transfer via heat recirculation is minimal, namely, heat recirculation affects the extinction behavior only slightly. Therefore, in contrast to the bell-like envelopes, the stability of the heat-recirculation micro-combustor represents a remarkably different behavior, with the critical heat loss coefficient continuously increasing with the decrease of wall thermal conductivity. A substantial enhancement in flame stability is observed employing lower-wall-thermal-conductivity materials. Additional transverse thermal transport within the heat-recirculation micro-combustor provides the necessary preheating that is limiting the single-channel microcombustor, suggesting that the heat-recirculation micro-combustor has the maximum effect of flame stability in the blowout regime.

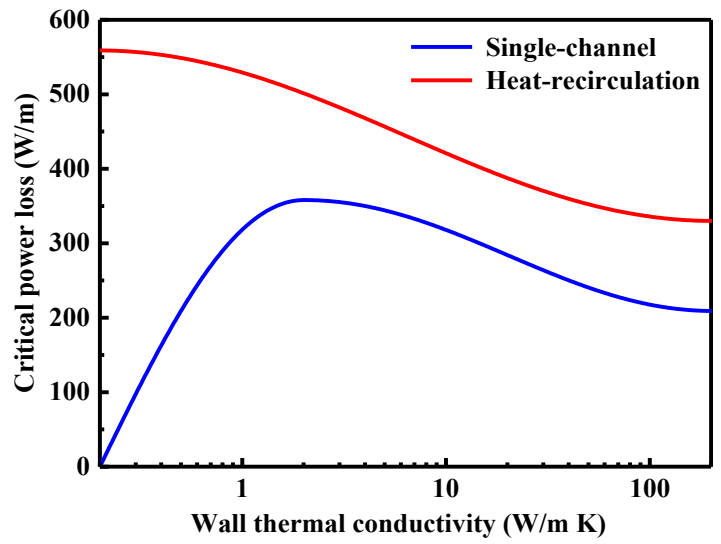

Fig. 5 Total critical power loss profiles of various wall thermal conductivities.

Another important measure of flame stability and combustion efficiency is the power lost through the walls. In cases where microcombustors are directly coupled through the wall with the reactor carrying out endothermic reactions, the power exchanged is actually an important measure of micro-combustor efficiency and capability. The power lost is not an equivalent measure to the heat transfer coefficient because of the temperature non-uniformity. The total power loss (or exchange) per unit length are plotted in Fig. 5, which defined as the amount of power lost through the walls under the critical conditions, corresponding to critical heat loss coefficients shown in Fig. 4. In general, the critical power loss exhibits qualitative behavior similar to that of the critical heat loss coefficient. However, there are also very interesting quantitative differences. With regard to the heat-recirculation microcombustor, the maximum critical power loss occurs for lower-wallthermal-conductivity materials. Moreover, for the two micro-scale systems, the critical power loss drops sharply above the wall thermal conductivity of approximately $2.0 \mathrm{~W} / \mathrm{m} \mathrm{K}$ and is fairly constant for high wall-thermal-conductivity materials. The heat-recirculation microcombustor provides higher power than the single-channel microcombustor, and the critical power loss increases continuously with the decrease of wall thermal conductivity and appears to plateau for lowwall-thermal-conductivity materials. Furthermore, the maximum critical power loss is a function of the temperature profile of the outer wall and the critical heat loss coefficient. For higher wall-thermal-conductivity materials, the critical heat loss coefficients are lower and the temperature profiles are more uniform. In contrast, lower wall-thermal-conductivity materials allow higher heat loss coefficients and hot spots within the micro-combustor.

In order to understand how to design micro-combustors with enhanced flame stability and robustness, it is necessary to understand the extinction and blowout behaviors. Fig. 6 shows centerline reaction-rate 
profiles for three different cases: a stable flame, one approaching extinction (corresponding to the circle symbol shown in Fig. 4, where the critical heat loss coefficient $h$ is $40.0 \mathrm{~W} / \mathrm{m}^{2} \mathrm{~K}$ and the wall thermal conductivity $k$ is $200.0 \mathrm{~W} / \mathrm{m} \mathrm{K}$ ), and one approaching blowout (corresponding to the circle symbol shown in Fig. 4, where the critical heat loss coefficient $h$ is $308.0 \mathrm{~W} / \mathrm{m}^{2} \mathrm{~K}$ and the wall thermal conductivity $k$ is $0.5 \mathrm{~W} / \mathrm{m} \mathrm{K}$ ). Qualitatively, when extinction occurs, the reaction region shifts downstream slightly and is broadened, while the maximum reaction rate reduces. The reaction is quenched without leaving the micro-combustor. On the other hand, as the micro-combustor approaches blowout, the reaction region shifts significantly downstream, without decreasing the reaction rate. In both cases, loss of flame stability is caused by a lack of upstream heat transfer to the incoming cold reactants. The primary difference between the two behaviors is as follow: in extinction, the excess heat loss occurs through the walls to the surroundings, whereas in blowout, more heat leaves in the form of a hot exit gas.

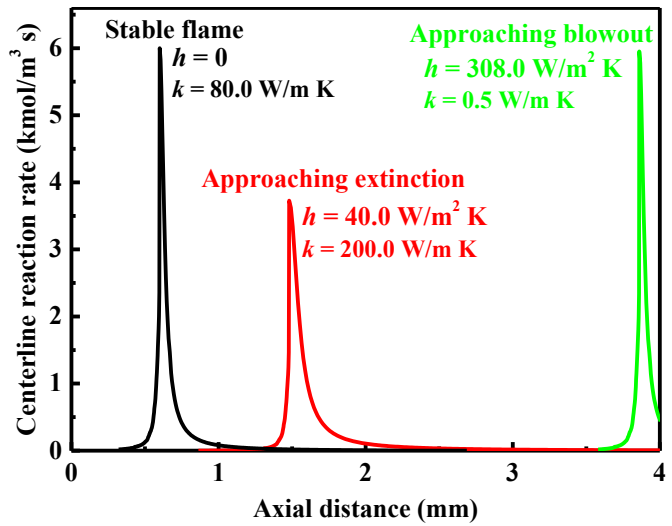

Fig. 6 Reaction rate as a function of axial distance for three typical cases, a stable flame, one approaching extinction from thermal losses, and one approaching blowout. Thermal quenching shifts the reaction downstream slightly, broadens the reaction region a bit, and reduces the maximum reaction rate, while blowout shifts the reaction region downstream significantly without decreasing the reaction rate.

The temperature and reaction rate profiles for highly conductive walls are depicted in Fig. 7 to elucidate heat recirculation affects flame stability. The outer walls stay temperature uniform with increasing cooling of the outer wall, as shown in Fig. 7a. In addition, the inner wall temperature profiles are also shown for two cases: heat loss coefficients of 0 and $40.0 \mathrm{~W} / \mathrm{m}^{2} \mathrm{~K}$. The latter approaches extinction mode, corresponding to the circle symbol shown in Fig. 4 and the red line shown in Fig. 6, where the critical heat loss coefficient $h$ is $40.0 \mathrm{~W} / \mathrm{m}^{2} \mathrm{~K}$ and the wall thermal conductivity $k$ is $200.0 \mathrm{~W} / \mathrm{m} \mathrm{K}$. The inner walls are nearly thermally uniform and their axial temperatures remains fairly constant. There are neither longitudinal nor transverse temperature gradients for adiabatic walls. However, some differences between the inner and outer wall temperatures are observed as the heat loss coefficient increases. Furthermore, the maximum reaction rate on the centerline reduces and the reaction region shifts downstream when more heat is removed from the micro-scale system, as shown in Fig. 7b. This behavior is indicative of the extinction mode of flame instability, which has been discussed in previous work of Norton and Vlachos (2003 and 2004) for the singlechannel micro-combustor. The reaction is quenched without leaving the micro-combustor, as compared with the blowout mode. The corresponding transverse temperature profiles approaching extinction for highly conductive walls at various axial distances are depicted in Fig. 7c. In each wall, negligible transverse temperature gradients are observed, consistent with the axial wall temperature gradients shown in Fig. 7a. However, gradients from the inner to the outer wall exist, indicating the walls act as heat sinks. Upstream of the flame (such as $0.5 \mathrm{~mm}$ ), the inner wall and the hot combustion products flowing next to it acts as a heat source preheating and igniting the cold incoming gases, but at the same time are responsible for heat losses to the outside wall. Downstream of the flame (such as $2.0 \mathrm{~mm}$ ), heat diffuses from the hot inner gascombustion channel toward the inner wall and then to the gasrecirculation channel and outer wall. This behavior is qualitatively similar to that found in a single channel. Under all conditions, the gasrecirculation channel and outer wall are fairly isothermal.

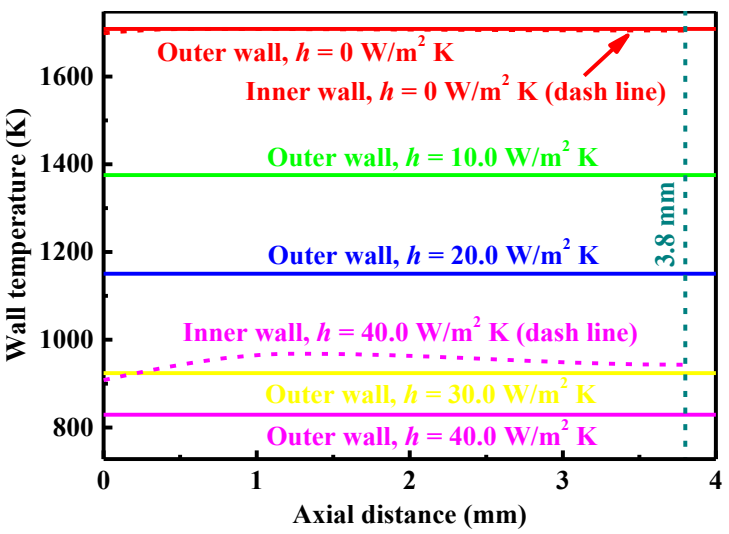

(a) Wall temperature (the dash vertical line represents the length of inner walls)

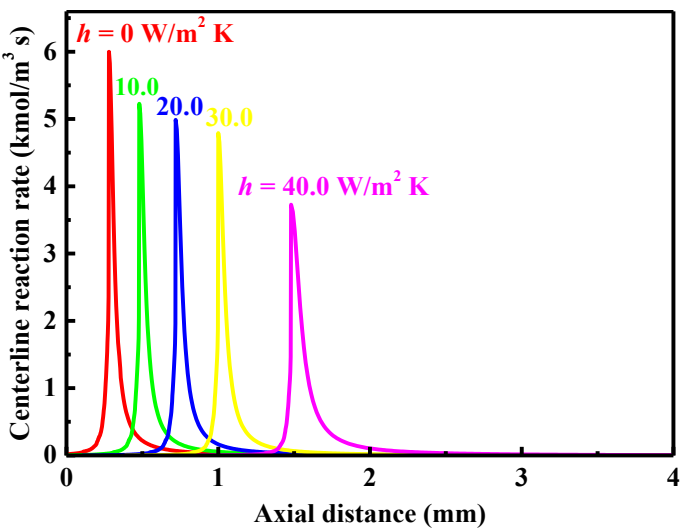

(b) Centerline reaction rate

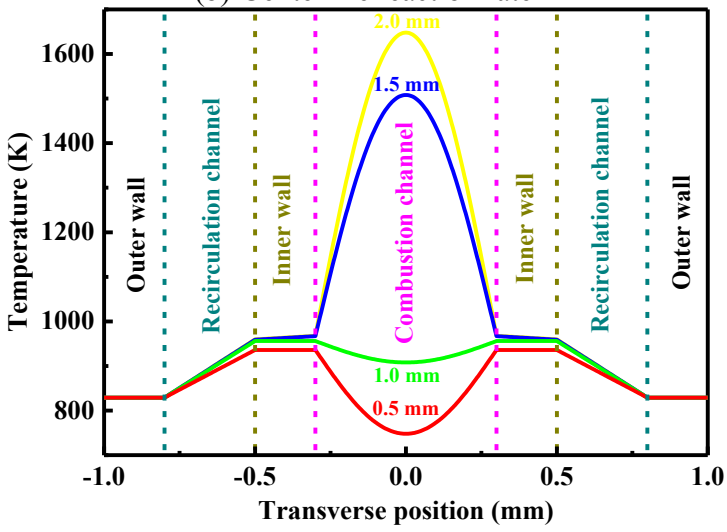

(c) Transverse temperature profiles approaching extinction at various axial distances $\left(h=40.0 \mathrm{~W} / \mathrm{m}^{2} \mathrm{~K}\right.$, the dash vertical lines represent the various interfaces)

Fig. 7 Temperature and reaction rate profiles for highly conductive walls $(k=200.0 \mathrm{~W} / \mathrm{m} \mathrm{K})$.

The corresponding temperature and reaction rate results for lowconductivity walls are shown in Fig. 8. For low heat loss coefficients (nearly adiabatic operation) and low-wall-thermal-conductivity materials $(k=0.5 \mathrm{~W} / \mathrm{m} \mathrm{K})$, both wall (inner and outer) temperatures keep 
increasing with the axial distance, and are extremely high, as shown in Fig. 8a. Furthermore, for intermediate heat loss coefficients (such as 80.0 $\mathrm{W} / \mathrm{m}^{2} \mathrm{~K}$ ) in the forced convection region, a maximum in wall temperatures are observed. This behavior is because the flame being localized within the central combustion channel, and the outer wall temperatures are moderate due to the intermediate heat loss coefficients. Finally, for high heat loss coefficients (approaching blowout that corresponds to the square symbol shown in Fig. 4 and the green line shown in Fig. 6, where the critical heat loss coefficient $h$ is $308.0 \mathrm{~W} / \mathrm{m}^{2} \mathrm{~K}$ and the wall thermal conductivity $k$ is $0.5 \mathrm{~W} / \mathrm{m} \mathrm{K}$ ), the maximum temperature occurs at the turn where the flame is anchored for a range of conditions. Blowout occurs once the flame is detached from the turn.

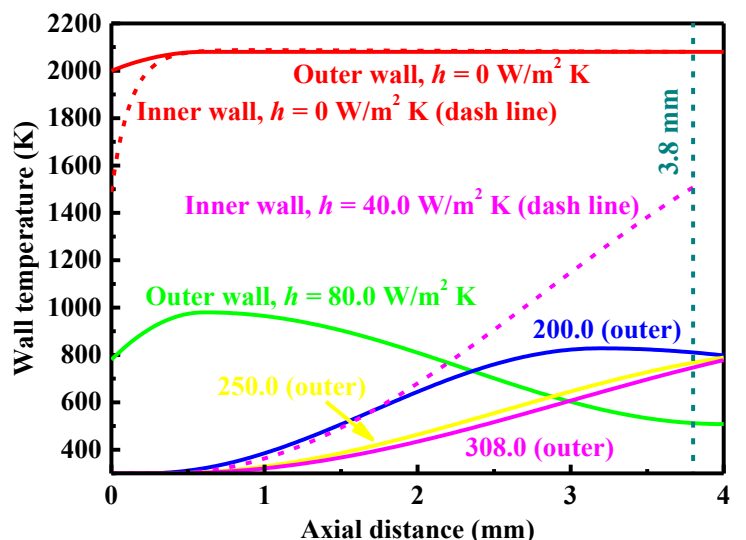

(a) Wall temperature (the dash vertical line represents the length of inner walls)

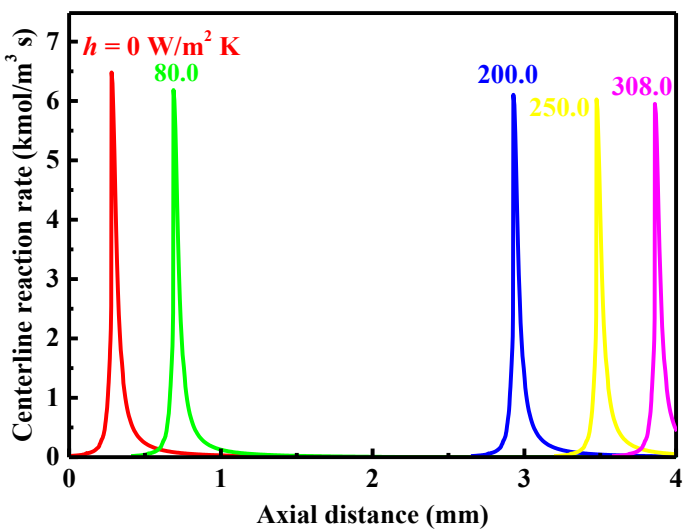

(b) Centerline reaction rate

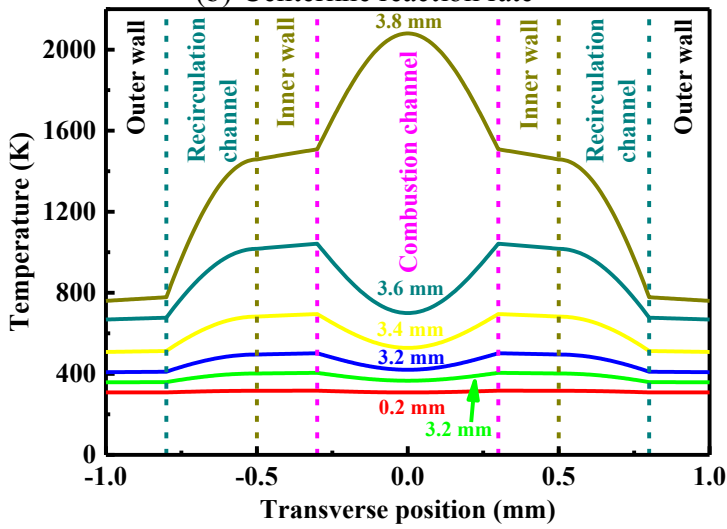

(c) Transverse temperature profiles approaching blowout at various axial distances $\left(h=308.0 \mathrm{~W} / \mathrm{m}^{2} \mathrm{~K}\right.$, the dash vertical lines represent the various interfaces)

Fig. 8 Temperature and reaction rate profiles for low-conductivity walls $(k=0.5 \mathrm{~W} / \mathrm{m} \mathrm{K})$.
Fig. $8 \mathrm{~b}$ demonstrates that the maximum of the centerline reaction rate is found to be relatively constant, approximately irrespective of heat loss coefficient, and in stark contrast to the approaching extinction mode as shown in Fig. 7b. This behavior is because the heat-recirculation micro-combustor being limited by axial heat transfer and represents the blowout limit of flame instability. The inner wall temperatures for the adiabatic $\left(h=0 \mathrm{~W} / \mathrm{m}^{2} \mathrm{~K}\right)$ and critical heat loss $\left(h=308.0 \mathrm{~W} / \mathrm{m}^{2} \mathrm{~K}\right)$ cases are also shown in Fig. 8a. The outer and inner wall temperatures are in thermal equilibrium, eliminating the hot spot of the micro-combustor. Fig. $8 \mathrm{c}$ shows the transverse temperature profiles approaching blowout $(h=$ $308.0 \mathrm{~W} / \mathrm{m}^{2} \mathrm{~K}$ ) of the heat-recirculation micro-combustor at various axial distances. Near the entrance (such as $0.2 \mathrm{~mm}$ ), small temperature gradients are observed. As one moves downstream, hot products and inner walls preheat the incoming cold reacting gases. Near the flame, the gases are hot and supply heat to the inner walls and this in turn to the products along with the outer walls. Unlike the highly conductive wall as shown in Fig. 7c, the transverse wall temperatures at various axial distances are not equivalent, consistent with the axial wall temperature gradients shown in Fig. 8a. Due to the heat localization and the preheating caused by heat recirculation, the heat-recirculation microcombustor can be sustained under high heat transfer coefficients and the outer wall temperatures are substantially lower than in the single-channel micro-combustor. The maximum outer wall temperature near blowout for low-thermal-conductivity wall case is approximately $760 \mathrm{~K}$, which is more practical for portable micro-scale power generation systems. Furthermore, the exit gases are practically at room temperature. In other words, it is possible for these micro-scale systems to harness all the combustion heat by exchanging it with micro-scale systems needing power.

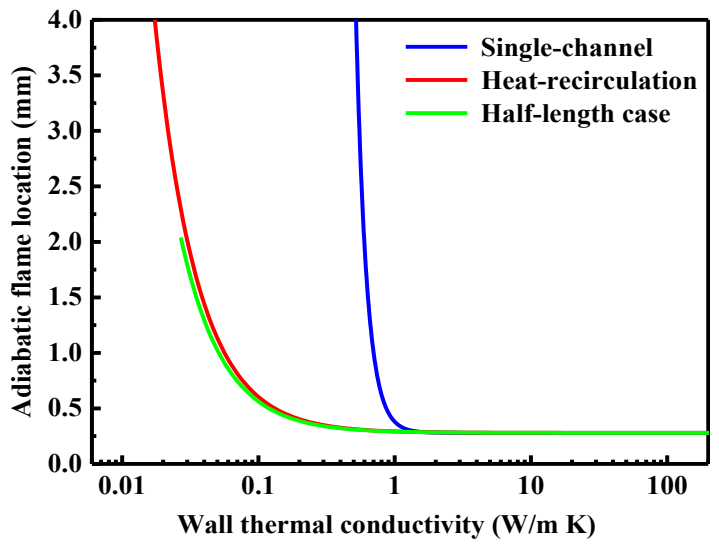

Fig. 9 Adiabatic flame location as a function of wall thermal conductivity for single-channel and various heat-recirculation micro-combustors.

Since the two recirculation-channels effectively double the overall length of the micro-combustor, the heat-recirculation micro-combustor has twice the residence time as compared with the single-channel microcombustor. For low-conductivity walls, the flame loses stability because of blowout. Therefore, in the heat-recirculation micro-combustor, the substantial increase in flame stability may be because of the longer residence time. However, we argue against this mechanism. This is rationalized in part because of the high fuel conversions (nearly complete conversion) obtained in our simulations, indicating that a longer microcombustor will not substantially affect the flame stability in terms of fuel conversion. A heat-recirculation micro-combustor was created with half the original length of the combustion chamber $(2.0 \mathrm{~mm})$ to make a comparison in flame stability for the micro-scale systems with the same residence time. This micro-combustor has the same residence time as the single channel and half of the surface area for heat losses. Kaisare and Vlachos (2007b) investigated the roles of heat loss and heat recirculation on the mechanisms of flame blowout and extinction in parallel plate 
micro-channels, and demonstrated that the length of micro-combustor plays a significant role in flame stability, i.e., as the length of microcombustor decreases, the flame stability increases for conditions limited by heat loss. The effect of wall thermal conductivity on adiabatic flame location for the half-length heat-recirculation micro-combustor is identical to the original case, as shown in Fig. 9. The only difference observed in the adiabatic flame location is that the thermal conductivity resulting in flame blowout is higher, since the length of the combustion region is halved. Fig. 10 shows the critical heat loss coefficient for the half-length heat-recirculation micro-combustor. For intermediate and high conductive walls, the half-length heat-recirculation microcombustor is slightly more stable than the original due to the lower surface area for heat loss. For low-thermal-conductivity walls, the half half-length heat-recirculation micro-combustor shows no difference in flame stability. Overall, it is clear that the enhanced flame stability of the heat-recirculation micro-combustor is not because of the longer residence time but rather to the preheating of the cold reactants that is the limiting factor at low thermal conductivities. The hot combustion products in the heat-recirculation micro-combustor act to increase the effective thermal conductivity of the inner walls by providing transversal heat exchange.

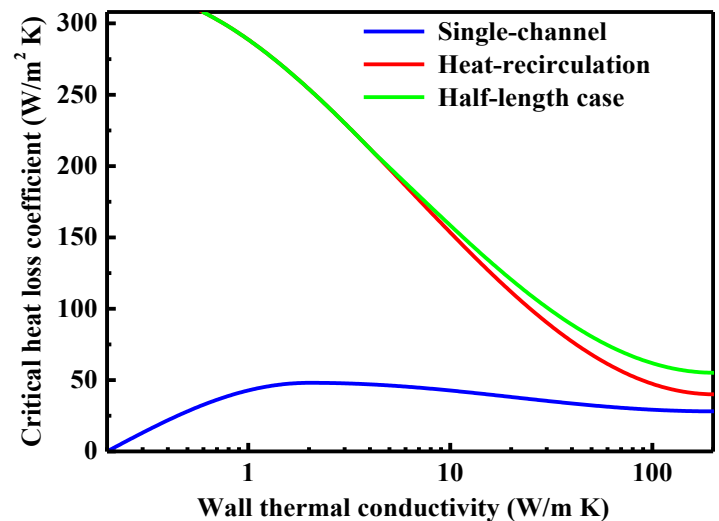

Fig. 10 Critical heat loss coefficient as a function of wall thermal conductivity for single-channel and various heat-recirculation micro-combustors.

\section{CONCLUSIONS}

The flame stability of premixed, stoichiometric propane-air mixtures in heat-recirculation micro-combustors was investigated and compared to single-channel micro-combustors. In the limit of highly conductive walls, a micro-scale system is susceptible to extinction and the flame stability of the two micro-scale systems is similar. In addition, highly conductive inner walls can provide the required preheating via axial wall conduction to stabilize flame and heat loss dominates, namely, heat recirculation has only minimal effect on the extinction behavior: it makes the combustion chamber (internal channel) warmer but it also increases the heat loss. In contrast, in the limit of low-conductivity walls, the heat-recirculation micro-combustor is much more stable than the single-channel microcombustor. Under this circumstance, the recirculating hot gases and the outer wall provide additional heat to the incoming cold reactants in the transverse direction to cause ignition and flame stabilization, namely, heat recirculation has a profound effect on the blowout behavior of flame stability loss. Furthermore, an interesting conclusion is that a change in preheating occurs, from heat exchange in the axial direction as seen in single-channel micro-combustors to that in the transverse direction from countercurrent recirculation gases in heat-recirculation microcombustors. Finally, the heat-recirculation micro-combustor exhibits some unique attributes for practical operation. While temperature gradients may exist in heat-recirculation micro-combustors with lowconductivity walls, it is entirely possible to have inlet/outlet streams exhibiting nearly room temperature, outer walls of only moderate temperatures, and high thermal and combustion efficiencies.

\section{ACKNOWLEDGEMENTS}

This work was supported by the Natural Science Foundation of China (No. 51506048).

\section{REFERENCES}

Ahn, J., Eastwood, C., Sitzki, L., and Ronney, P.D., 2005, "Gas-phase and catalytic combustion in heat-recirculating burners," Proceedings of the Combustion Institute, 30(2), 2463-2472. http://dx.doi.org/10.1016/j.proci.2004.08.265

Baigmohammadi, M., Tabejamaat, S., and Farsiani, Y., 2015a, "An experimental study of methane-oxygen-carbon dioxide premixed flame dynamics in non-adiabatic cylinderical meso-scale reactors with the backward facing step," Chemical Engineering and Processing: Process Intensification, 95, 105-123. http://dx.doi.org/10.1016/j.cep.2015.05.013

Baigmohammadi, M., Tabejamaat, S., and Farsiani, Y., 2015b, "Experimental study of the effects of geometrical parameters, Reynolds number, and equivalence ratio on methane-oxygen premixed flame dynamics in non-adiabatic cylinderical meso-scale reactors with the backward facing step," Chemical Engineering Science, 132, 215-233. http://dx.doi.org/10.1016/j.ces.2015.04.008

Belmont, E.L., and Ellzey, J.L., 2014, "Lean heptane and propane combustion in a non-catalytic parallel-plate counter-flow reactor," Combustion and Flame, 161(4), 1055-1062.

http://dx.doi.org/10.1016/j.combustflame.2013.10.026

Belmont, E.L., Radyjowski, P., and Ellzey, J. L., 2015, "Effect of geometric scale on heat recirculation and syngas production in a noncatalytic counter-flow reformer," Combustion Science and Technology, 187(6), 874-893. http://dx.doi.org/10.1080/00102202.2014.978864

Belmont, E.L., Schoegl, I., and Ellzey, J.L., 2013, "Experimental and analytical investigation of lean premixed methane/air combustion in a mesoscale counter-flow reactor," Proceedings of the Combustion Institute, 34(2), 3361-3367. http://dx.doi.org/10.1016/j.proci.2012.06.087

Boyarko, G.A., Sung, C.-J., Schneider, S.J., 2005, "Catalyzed combustion of hydrogen-oxygen in platinum tubes for micro-propulsion applications," Proceedings of the Combustion Institute, 30(2), 24812488.

http://dx.doi.org/10.1016/j.proci.2004.08.203

Cameretti, M.C., and Tuccillo, R., 2015, "Combustion features of a biofuelled micro-gas turbine," Applied Thermal Engineering, 89(5), 280290.

http://dx.doi.org/10.1016/j.applthermaleng.2015.05.057

Chen, C.-H., and Ronney, P.D., 2011, "Three-dimensional effects in counterflow heat-recirculating combustors," Proceedings of the Combustion Institute, 33(2), 3285-3291.

http://dx.doi.org/10.1016/j.proci.2010.06.081

Chen, C.-H., and Ronney, P.D., 2013, "Scale and geometry effects on heat-recirculating combustors," Combustion Theory and Modelling, 17(5), 888-905.

http://dx.doi.org/10.1080/13647830.2013.812807

Fan, A., Wan, J., Maruta, K., Yao, H., and Liu, W., 2013, "Interactions between heat transfer, flow field and flame stabilization in a microcombustor with a bluff body," International Journal of Heat and Mass Transfer, 66, 72-79. 


\section{http://dx.doi.org/10.1016/j.ijheatmasstransfer.2013.07.024}

Federici, J.A., Norton, D.G., Brüggemann, T., Voit, K.W., Wetzel, E.D., and Vlachos, D.G., 2006, "Catalytic microcombustors with integrated thermoelectric elements for portable power production," Journal of Power Sources, 161(2), 1469-1478.

http://dx.doi.org/10.1016/j.jpowsour.2006.06.042

Federici, J.A., and Vlachos, D.G., 2008, "A computational fluid dynamics study of propane/air microflame stability in a heat recirculation reactor," Combustion and Flame, 153(1-2), 258-269.

http://dx.doi.org/10.1016/j.combustflame.2007.09.009

Federici, J.A., and Vlachos, D.G., 2011, “Experimental studies on syngas catalytic combustion on $\mathrm{Pt} / \mathrm{Al}_{2} \mathrm{O}_{3}$ in a microreactor," Combustion and Flame, 158(12), 2540-2543.

http://dx.doi.org/10.1016/j.combustflame.2011.05.003

Federici, J.A., Wetzel, E.D., Geil, B.R., and Vlachos, D.G., 2009, "Single channel and heat recirculation catalytic microburners: An experimental and computational fluid dynamics study," Proceedings of the Combustion Institute, 32(2), 3011-3018.

http://dx.doi.org/10.1016/j.proci.2008.07.005

Ju, Y., and Choi, C.W., 2003, "An analysis of sub-limit flame dynamics using opposite propagating flames in mesoscale channels," Combustion and Flame, 133(4), 483-493.

http://dx.doi.org/10.1016/s0010-2180(03)00058-0

Kaisare, N.S., Deshmukh, S.R., and Vlachos, D.G., 2008, "Stability and performance of catalytic microreactors: Simulations of propane catalytic combustion on Pt," Chemical Engineering Science, 63(4), 1098-1116. http://dx.doi.org/10.1016/j.ces.2007.11.014

Kaisare, N.S., Stefanidis, G.D., and Vlachos, D.G., 2009, "Millisecond production of hydrogen from alternative, high hydrogen density fuels in a cocurrent multifunctional microreactor," Industrial \& Engineering Chemistry Research, 48(4), 1749-1760.

http://dx.doi.org/10.1021/ie800392z

Kaisare, N.S., and Vlachos, D.G., 2007a, "Extending the region of stable homogeneous micro-combustion through forced unsteady operation," Proceedings of the Combustion Institute, 31(2), 3293-3300.

http://dx.doi.org/10.1016/j.proci.2006.07.031

Kaisare, N.S., and Vlachos, D.G., 2007b, "Optimal reactor dimensions for homogeneous combustion in small channels," Catalysis Today, 120(1), 96-106.

http://dx.doi.org/10.1016/j.cattod.2006.07.036

Karim, A.M., Federici, J.A., and Vlachos, D.G., 2008, "Portable power production from methanol in an integrated thermoeletric/microreactor system," Journal of Power Sources, 179(1), 113-120.

http://dx.doi.org/10.1016/j.jpowsour.2007.12.119

Kizaki, Y., Nakamura, H., Tezuka, T., Hasegawa, S., and Maruta, K., 2015, "Effect of radical quenching on $\mathrm{CH}_{4} /$ air flames in a micro flow reactor with a controlled temperature profile," Proceedings of the Combustion Institute, 35(3), 3389-3396.

http://dx.doi.org/10.1016/j.proci.2014.07.030

Kuo, C.H., and Ronney, P.D., 2007, "Numerical modeling of nonadiabatic heat-recirculating combustors," Proceedings of the Combustion Institute, 31(2), 3277-3284.

http://dx.doi.org/10.1016/j.proci.2006.08.082

Kurdyumov, V.N., and Matalon, M., 2011, "Analysis of an idealized heat-recirculating microcombustor," Proceedings of the Combustion Institute, 33(2), 3275-3284.

http://dx.doi.org/10.1016/j.proci.2010.07.041
Leach, T.T., and Cadou, C.P., 2005, "The role of structural heat exchange and heat loss in the design of efficient silicon micro-combustors," Proceedings of the Combustion Institute, 30(2), 2437-2444. http://dx.doi.org/10.1016/j.proci.2004.08.229

Norton, D.G., and Vlachos, D.G., 2003, “Combustion characteristics and flame stability at the microscale: a CFD study of premixed methane/air mixtures," Chemical Engineering Science, 58(21), 4871-4882. http://dx.doi.org/10.1016/j.ces.2002.12.005

Norton, D.G., and Vlachos, D.G., 2004, “A CFD study of propane/air microflame stability," Combustion and Flame, 138(1-2), 97-107. http://dx.doi.org/10.1016/j.combustflame.2004.04.004

Norton, D.G., Wetzel, E.D., and Vlachos, D.G., 2004, "Fabrication of single-channel catalytic microburners: Effect of confinement on the oxidation of hydrogen/air mixtures," Industrial \& Engineering Chemistry Research, 43(16), 4833-4840.

http://dx.doi.org/10.1021/ie049798b

Park, J., Lee, S., Wu, H., and Kwon, O., 2012, "Thermophotovoltaic power conversion from a heat-recirculating micro-emitter," International Journal of Heat and Mass Transfer, 55(17-18), 4878-4885. http://dx.doi.org/10.1016/j.ijheatmasstransfer.2012.05.001

Patankar, S.V., and Spalding, D.B., 1972, "A calculation procedure for heat, mass and momentum transfer in three-dimensional parabolic flows," International Journal of Heat and Mass Transfer, 15(10), 1787-1806. http://dx.doi.org/10.1016/0017-9310(72)90054-3

Raimondeau, S., Norton, D., Vlachos, D.G., and Masel, R.I., 2002, "Modeling of high-temperature microburners," Proceedings of the Combustion Institute, 29(1), 901-907. http://dx.doi.org/10.1016/s1540-7489(02)80114-6

Ronney, P.D., 2003, "Analysis of non-adiabatic heat-recirculating combustors," Combustion and Flame, 135(4), 421-439.

http://dx.doi.org/10.1016/j.combustflame.2003.07.003

Saito, M., Kojima, J., Iwai, H., and Yoshida, H., 2015, “The limiting process in steam methane reforming with gas diffusion into a porous catalytic wall in a flow reactor," International Journal of Hydrogen Energy, 40(29), 8844-8855.

http://dx.doi.org/10.1016/j.ijhydene.2015.05.073

Scarpa, A., Pirone, R., Russo, G., and Vlachos, D.G., 2009, "Effect of heat recirculation on the self-sustained catalytic combustion of propane/air mixtures in a quartz reactor," Combustion and Flame, 156(5), 947-953.

http://dx.doi.org/10.1016/j.combustflame.2008.11.005

Shirsat, V., and Gupta, A.K., 2011, "A review of progress in heat recirculating meso-scale combustors," Applied Energy, 88(12), 42944309.

http://dx.doi.org/10.1016/j.apenergy.2011.07.021

Simagina, V.I., Ozerova, A.M., Komova, O.V., Odegova, G.V., Kellerman, D.G., Fursenko, R.V., Odintsov, E.S., and Netskina, O.V., 2015, "Cobalt boride catalysts for small-scale energy application," Catalysis Today, 242(Part A), 221-229.

http://dx.doi.org/10.1016/j.cattod.2014.06.030

Stefanidis, G.D., and Vlachos, D.G., 2009, "Controlling homogeneous chemistry in homogeneous-heterogeneous reactors: Application to propane combustion," Industrial \& Engineering Chemistry Research, 48(13), 5962-5968.

http://dx.doi.org/10.1021/ie801480m

Vaccaro, S., Malangone, L., and Ciambelli, P., 2010, "Micro-scale catalytic reactor for syngas production," Industrial \& Engineering Chemistry Research, 49(21), 10924-10933. 
Westbrook, C.K., and Dryer, F.L., 1981, "Simplified reaction mechanisms for the oxidation of hydrocarbon fuels in flames," Applied Energy, 27(1-2), 31-43.

http://dx.doi.org/10.1080/00102208108946970

Wierzbicki, T.A., Lee, I.C., and Gupta, A.K., 2014, "Combustion of propane with $\mathrm{Pt}$ and $\mathrm{Rh}$ catalysts in a meso-scale heat recirculating combustor," Applied Energy, 130, 350-356.

http://dx.doi.org/10.1016/j.apenergy.2014.05.069

Wierzbicki, T.A., Lee, I.C., and Gupta, A.K., 2015, "Rh assisted catalytic oxidation of jet fuel surrogates in a meso-scale combustor," Applied Energy, 145, 1-7.

http://dx.doi.org/10.1016/j.apenergy.2015.01.097

Yan, Y., Pan, W., Zhang, L., Tang, W., Chen, Y., and Li, L., 2015, "Numerical study of the geometrical parameters on $\mathrm{CH}_{4} /$ air premixed combustion in heat recirculation micro-combustor," Fuel, 159, 45-51. http://dx.doi.org/10.1016/j.fuel.2015.06.069

Yang, W., Fan, A., Wan, J., and Liu, W., 2015, "Effect of external surface emissivity on flame-splitting limit in a micro cavity-combustor," Applied Thermal Engineering, 83, 8-15.

http://dx.doi.org/10.1016/j.applthermaleng.2015.03.009

Zhong, B.-J., and Wang, J.-H., 2010, "Experimental study on premixed $\mathrm{CH}_{4} /$ air mixture combustion in micro Swiss-roll combustors," Combustion and Flame, 157(12), 2222-2229.

http://dx.doi.org/10.1016/j.combustflame.2010.07.014

Zimont, V.L., 2015, "Theoretical study of self-ignition and quenching limits in a catalytic micro-structured burner and their sensitivity analysis," Chemical Engineering Science, 134, 800-812.

http://dx.doi.org/10.1016/j.ces.2015.06.007 